\title{
The Current Situation and Suggestions of Preschool Chinese Bilingual Education in Ethnic Minority Areas
}

\author{
Xiaoxi Wang, Min Tang \\ School of preschool and special education, Kunming University, Kunming, China
}

\begin{abstract}
Mother tongue plays an important role in the growth and development of national individuals and groups. In addition to taking active protective measures, the state must also effectively inherit and develop through education. Children are at a critical stage of language learning. In the period of the largest voice plasticity, it is of great significance to carry out pre-school bilingual education in ethnic areas for the development, inheritance and protection of national culture and for children's future national identity. At present, bilingual education has been carried out in the provinces with concentrated ethnic groups. The common modes of bilingual education and the results are achieved. The problems existing in the current bilingual education are analyzed, and suggestions for the future development from the aspects of kindergarten construction, parent education, curriculum construction and so on are put forward.
\end{abstract}

Keywords: ethnic areas; preschool education; bilingual education.

\section{The Significance of Bilingual Education}

China is a multi-ethnic and multilingual country, in the process of its development, all ethnic groups have created, enriched and developed their own language, and each language carries the profound historical culture and national quality of the nation, which is the most direct and concentrated embodiment of the rich traditional culture and traditional experience of the nation for thousands of years. Mother tongue plays an important role in the growth and development of national individuals and groups. In addition to taking active protective measures, the state must also effectively inherit and develop through education. However, the development of a nation's language and culture can never be closed development, especially in today's world economic integration and multi-cultural development pattern, if all ethnic groups want to continuously develop and progress, and better integrate into modern civilization society, each ethnic group must not only inherit their own language and traditional culture, but also learn national common language and mainstream National culture, as well as the languages and cultures of other developed countries in the world. Therefore, the state actively advocates bilingual education in ethnic minority areas.

Children are at a critical stage of language learning. In the period of the most plasticity of speech, the oral muscles are more elastic and have the most receptive ability to pronunciation. At the same time, early childhood is the fastest growing period of vocabulary. Children's ability to accept, imitate and memorize is strong and suitable for learning a second language. Learning a second language can make children's speech organs get full exercise. "Early childhood is an important period for language development, especially for oral development" and "5-6-year-old children can speak the language and Putonghua of their own nation or region with correct and clear pronunciation" are written in the guide for learning and development of 3-6-year-old children formulated and issued by the Ministry of education. Children in areas inhabited by ethnic minorities can basically speak Mandarin. Therefore, the outline of the national medium- and long-term education reform and development plan (2010-2020) points out that "bilingual teaching should be vigorously promoted. We will comprehensively offer Chinese courses, promote the use of the national language, respect and protect the right of ethnic minorities to receive education in their own language, and pay attention to strengthening bilingual education before school. " 


\section{Current Situation of Bilingual Education in China}

\subsection{Current Situation of Bilingual Education in Ethnic Areas}

Bilingual teaching in kindergartens refers to that in kindergartens, under the guidance of teachers with purpose, planning and organization, children choose appropriate teaching content, teaching organization and teaching methods, design corresponding teaching activity programs, evaluate and reflect on teaching results, so as to promote children's initial mastery of the national language, Gradually learning and mastering the second language is a kind of teaching activity to promote the all-round development of children's body and mind. [1] At present, bilingual education in China has been carried out for a long time, and the system is relatively perfect in Xinjiang, Inner Mongolia, Qinghai and Tibet. These areas are characterized by a relatively single ethnic group, so it is easier to concentrate resources to train bilingual teachers and build bilingual kindergartens. Xinjiang has basically achieved the goal of popularizing bilingual kindergarten education for two years before school in 2012 [2]; "during the 13th five year plan", Inner Mongolia will implement a public system for the preschool education of Mongolian and Chinese bilingual teaching, and focus on remote and poor areas, border areas, areas inhabited by ethnic minorities, etc., to promote the "three-year action plan for preschool education", by setting up people in relevant areas Ethnic minority kindergartens, increasing teachers and improving the conditions for running kindergartens will strive to achieve a gross enrollment rate of more than $90 \%$ of minority children's preschool education by 2017 [3]; as of 2014, there are 394 kindergartens in Tibetan areas of six prefectures in Qinghai Province, with 124 preschool classes attached to primary and secondary schools, with a gross enrollment rate of $50.87 \%$ in the first three years, and a teacher-student ratio of 1:22 [4].

\subsection{Existing Problems.}

In the provinces where ethnic minorities are concentrated, there are still some outstanding problems in preschool Chinese bilingual education. First, the number of kindergartens is insufficient to meet the needs of preschool children [1] [3] [4] [5].

Second, parents need to strengthen the concept of preschool education. In some minority areas, there is still the thought of "useless preschool education" in rural and pastoral areas [4], and parents still have no clear understanding of the role and significance of preschool education [6].

Third, the lack of teachers and the low quality of teachers, preschool bilingual education is inseparable from high-quality bilingual teachers, but the lack of teachers is a very prominent problem in the development of bilingual kindergartens in all ethnic areas $[2,4,6,7]$; although there are courses of bilingual education in Universities in ethnic areas and colleges and universities directly under the State Ethnic Affairs Commission, these teachers are in quantity It is far from meeting the needs of bilingual teaching in ethnic areas. At present, most of the professional bilingual teachers mainly serve the compulsory education, and few of them can serve the preschool education. In addition to the quantitative problems, the teaching skills of bilingual teachers need to be further improved. The requirements of kindergarten teachers' professional standards for kindergarten teachers include the creation and utilization of environment, the organization and care of one-day life, the support and guidance of game activities, the planning and implementation of educational activities, encouragement and evaluation, communication and cooperation, reflection and development aspects, etc. [8]. In addition to the basic quality of kindergarten teachers, teachers in bilingual kindergartens should also have good bilingual ability. The training of bilingual teachers in American primary and secondary schools includes professional ideal and correct values of bilingual education, unique knowledge structure of bilingual education, higher academic level of bilingual education, flexible wisdom of bilingual education, etc. [9].

Fourth, the problem of teaching materials. In order to cooperate with the bilingual teaching of people and Chinese, every place needs to have a set of teaching materials suitable for the actual situation of the place. At present, a set of 6 pre-school education textbooks has been compiled in Xinjiang and has been put into use [10]. Although there is a certain exploration in the compilation of teaching materials in other areas [6] [11], a perfect curriculum and textbook system has not yet been 
formed. Fourth, the construction of quality supervision body and teacher training department is not perfect [1] [6] [7]. On the one hand, due to the lack of supervision, there is a situation that the teaching is more arbitrary and the teaching quality is difficult to guarantee; on the other hand, the teachers are not better, lack of guidance and guidance. Therefore, the implementation of bilingual education in minority kindergartens should have a set of perfect evaluation and incentive mechanism, so that teachers have laws to follow, guidelines to read and resources to find.

\section{Countermeasures and Suggestions}

\subsection{Accelerate the Construction of Kindergartens in Ethnic Areas}

In the construction of kindergartens, the construction of kindergartens in ethnic areas is mainly led by the state forces, because there are many remote areas in ethnic areas. At present, the country is vigorously promoting the construction of "one village, one kindergarten". From the hardware of school building construction to the software of teachers' allocation, the construction is mainly supported by the national and provincial financial allocations. In addition to the support of the state, we should also actively introduce the support of enterprises and charities to promote the construction of kindergartens and the development of early childhood education in ethnic areas.

\subsection{Strengthen Parent Education}

To educate the parents of children in ethnic areas on science popularization, so that they can understand the great value of kindergarten for children's development. At the same time, it is also necessary to educate parents to pass on the awareness of their own national culture. Family education is the first position to preserve the national language. If the family is unable to create a national language speaking environment for children, it is difficult for children to learn the national language, which will cause obstacles to their future development of national identity.

\subsection{Training Teachers for Bilingual Education of Ethnic Minorities}

The teacher training of bilingual education should start from ethnic areas. Teachers of bilingual kindergartens need to master the knowledge of national language, Chinese and pre-school education skills. Among these skills, language learning takes the longest time, so it is necessary to give priority to find teachers who can speak Chinese and minority language in ethnic areas, and train them in preschool education related knowledge. As the distribution of ethnic areas in China is mainly in remote mountainous areas and poverty-stricken areas, we should consider relaxing the requirements of teacher recruitment when training bilingual teachers, such as the restrictions on education background and major. The state should train the existing preschool teachers in ethnic areas by means of state training and post replacement learning, and at the same time, consciously set up the training courses for the teachers of bilingual education in ethnic areas. Governments and education departments in ethnic areas shall organize experts to carry out door-to-door service training for kindergartens. Finally, kindergartens also need continuous kindergarten-based training and research. We need to build a teacher training system with national leadership, local support and park-based cooperation.

\subsection{Build a Batch of Curriculum Resources for Ethnic Minority Preschool Chinese Bilingual Education}

In order to ensure the vigorous vitality of kindergarten education, we should not only follow the basic educational concept and spirit of scientific preschool education, but also take root in national culture and highlight national culture. The education for children in ethnic areas can't copy the existing courses, so we must develop the courses related to children's life experience in ethnic areas according to local conditions to truly meet the educational needs of ethnic areas, such as art education combined with ethnic music and dance, language education combined with ethnic folk stories, physical education combined with ethnic sports, etc. Only by absorbing nutrition from national culture can education truly rooted in ethnic areas have strong vitality. 


\section{Conclusion}

At present, Chinese bilingual education in our country has been carried out in the provinces inhabited by ethnic groups, and has achieved certain results. However, there are still problems in the popularization of preschool education, the construction of teachers and the construction of curriculum. In the future, preschool Chinese bilingual education will not only be carried out in the provinces where ethnic groups live together, but also in the provinces and regions where ethnic groups live together. On the basis of the existing, we must start from the aspects of kindergarten hardware construction, teacher training and curriculum development to promote the popularization and development of preschool Chinese bilingual education.

\section{References}

[1]. Shao Mingxing. (2015). Discussion on the implementation of bilingual education in minority kindergartens. Education and teaching research, 29 (7).

[2]. Kong Lingjuan (2016). Effective ways to improve bilingual ability of Xinjiang minority children. Theoretical observation (3).

[3]. news from this journal. (2016). Inner Mongolia will speed up the development of ethnic education in pre-school compulsory education. China's out of school education: the last ten days (5), 172-172.

[4]. Wang Rong, \&amp; Shang ma. (2014). The current situation and Prospect of Tibetan Chinese bilingual education in Qinghai Tibetan area. Journal of Qinghai Normal University (PHIL OSOPHY AND SOCIAL SCIENCES EDITION), 36 (4), 118-120.

[5]. Xing Junli, \&amp; Li Xuelian. (2012). The current situation, problems and Countermeasures of Tibet preschool education. Journal of Tibet University (SOCIAL SCIENCES EDITION), 27 (4), 160-164.

[6]. Yao Jianjun. (2014). Research on the development of Tibetan Chinese bilingual education in Tibet. Journal of Hubei University of science and Technology (7), 92-93.

[7]. Li Zelin. The dilemma and breakthrough of Chinese bilingual teacher training in China [J]. Journal of Northwest Normal University (SOCIAL SCIENCE EDITION), 2014 (2).

[8]. Liu Zhanlan (2012). Professional competence of kindergarten teachers. Preschool Education Research (11), 3-9.

[9]. Buto, Kathleen A. And Others. (1975). A Better Chance to Learn: Bilingual-Bicultural Education. Clearinghouse Publication No. 51. A better chance to learn, bilingual bicultural education.

[10]. Sun Yuhua, \&amp; Feng Jiangying. (2008). The promotion and thinking of Chinese bilingual education for preschool people in Xinjiang. Preschool Education Research (10).

[11]. Wang Meiying (2017). Study on the problems and solutions of Liangshan Yi's preschool education. Ethnic Education Research (01), 62-68. 